\title{
PARMENTIER, LAS PATATAS Y LAS OLLAS AMERICANAS
}

\section{Jean-Pierre Clément}

\section{RESUMEN}

El descubrimiento de nuevas posibilidades agroalimentarias fue uno de los más importantes motivos de las numerosas expediciones científicas enviadas a América durante el siglo XVIII. Algunos científicos galos (naturalistas, médicos, botánicos, etc.,) emprendieron, en la segunda mitad del siglo de las Luces, una activa campaña en favor del consumo de la patata por los hombres. El más conocido fue el farmacéutico Parmentier, que asentó su propaganda sobre argumentos politicos (la patata da de comer a toda la población), económicos (es una planta fácil de cultivar y de buen rendimiento), y científicos (excelentes cualidades nutritivas).

\section{SUMMARY}

The discovery of new agricultural and alimentary possibilities was one of the most important motives of the numerous scientific expeditions sent to America during the XVIIIth Century. Some French scientists (naturalists, medical, botanical, etc.,) undertook, during the second half of the Enlightment Century, an active campaign in favor of the potato consumption. The most wellknown was the pharmacist Parmentier that settled his propaganda upon political arguments (the potato gives of eating all the population), economical (it is an easy plant of cultivating and of good efficiency), and scientific (excellent nutritious qualities). 


\section{JEAN-PIERRE CLÉMENT}

Cuando se observa la sociedad del Antiguo Régimen, en Europa y aún más en América, se ve que la miseria fue uno de sus rasgos dominantes. Desde los mendigos y otros pícaros del Siglo de Oro español hasta los trabajadores indios forzados de los obrajes americanos pasando por los mujicos rusos, los braceros franceses del campo o los obreros ingleses de la industria textil, la inmensa mayoría de la población vivía en condiciones difíciles, a veces muy difíciles. El alimento, sobre todo, era lo que faltaba muy a menudo. Era tanto menos abundante cuanto que el crecimiento demográfico era considerable, en particular durante el siglo XVIII: entre 1700 y 1789, Europa pasó de 118 a 180 millones de habitantes, o sea una progresión de más del $52 \%$. La agricultura tradicional, rutinaria, no lograba satisfacer plenamente las necesidades de esta población en fuerte aumento; se entiende, pues, la voluntad de reforma de los ilustrados españoles (Informe sobre la ley agraria, de Jovellanos, por ejemplo), la aparición de numerosos progresos técnicos (como el arado de dos rejas en Francia) y las tentativas de difusión de tales avances (por las Sociedades Económicas de Amigos del País en España, o por las academias y las sociedades sabias en Inglaterra y en Francia).

\section{La falta de alimento y el interés por la Botánica}

Aquel mismo siglo XVIII había comenzado con una crisis, «la penuria horrible de 1709", como la llama Voltaire ${ }^{1}$, que venía tras un bajón en la producción agrícola (y por lo tanto en la alimenticia) y que había alcanzado a toda Europa de 1670 a 1695. De un modo general, en aquellos tiempos, en cuanto se descomponía algo el clima - demasiada lluvia hacía pudrir el grano en su tallo o una fuerte sequía impedía su desarrollo--, la producción se reducía en proporciones que podían resultar catastróficas y provocar la desaparición de un 10, y hasta un $20 \%$, de la población en algunas provincias francesas. Fueron entonces las hambrunas, siempre renovadas, de 1739-40, 1770, 1785, 1787-89, para no mencionar más que las más graves y más generales.

Estas crisis provocaban, además de la muerte de un sinnúmero de míseros, graves disturbios: ataques a depósitos de granos, pillajes de

\footnotetext{
1 Voltaire (1826), Dictionnaire philosophique, París: Forlic et Verdière, vol. 3, art.
} «Blé», p. 16. 
panaderías, saqueos de ciudades y pueblos, como en el caso de la famosa guerra de las Harinas en abril y mayo de $1775^{2}$.

Los gobiernos, pues, debían por humanidad como por necesidad responder a las necesidades alimenticias de sus vasallos. También lo deseaban, puesto que se situaban en una línea ideológica poblacionista que, si no era nada nueva, estaba muy en boga en el siglo de las Luces: se opinaba que sólo una población numerosa -fuerza económica y militar a la vez - podía hacer la potencia de un Estado. Dicha concepción explica el éxito de las tesis higienistas: la gente con responsabilidades, cualesquiera fueran, de cualquier tipo o nivel que fueran, trató de proteger la vida humana; de ahí el auge prodigioso, en el siglo XVIII, de las ciencias relacionadas con la salud (Medicina, Farmacia, etc.).

La Botánica desempeñó así un papel esencial en esta empresa al servicio del hombre. Además de que da riquezas económicas (tejidos, y tintes, por ejemplo) y tesoros farmacéuticos (la quina, para sólo mencionar el más célebre), esta ciencia ofrece también alimentos nuevos. Este aspecto es el que nos interesa aquí.

Los gobiernos europeos -el francés y el español, en particular- se lanzaron entonces a la caza de plantas nuevas, gracias a numerosas expediciones botánicas, de las cuales muchas tuvieron América por teatro de búsqueda. Al resumir los esfuerzos emprendidos en esta dirección, el Mercurio Peruano escribía en el último decenio del siglo:

No hay expedición marítima, no vemos viajero que no lleve el honroso empeño de conducir a su patria cuanto puede colectar de vegetales exóticos ${ }^{3}$.

En Francia, Turgot, cuando llegó al poder en París, en 1774, puso estas ideas en práctica; declaró entonces:

\footnotetext{
2 Ver CLÉMENT, Jean-Pierre (1994), «Réflexions sur la politique scientifique française vis-à-vis de l'Amérique espagnole au siècle des Lumières», de próxima aparición en Nouveau Monde et Renouveau de l'Histoire naturelle. Paris: C.I.A.E.C. y Madrid: C.S.I.C., vol. III.

3 González Laguna, P. Francisco (1794), «Memoria de las plantas extrañas que se cultivan en Lima introducidas en los últimos 30 años hasta el de 1794», Lima, Mercurio Peruano, XI, 367, 10 julio, p. 164.
} 


\section{JEAN-PIERRE CLÉMENT}

Es uno de los mejores bienes que se puedan hacer ante Dios y de los más satisfactorios para la conciencia el introducir y multiplicar así en un país producciones y cultivos nuevos ${ }^{4}$.

Esta ambición teórica encontró su concreción en el envío, en 1777, del botánico Joséph Dombey al Perú; iba acompañado por Hipólito Ruiz y José Pavón, pero la idea primera fue del gobierno francés, acorralado por las hambres repetidas:

Su Majestad, en vista a concurrir al progreso de los descubrimientos interesantes para la historia natural, ha aprobado que el señor Dombey, médico por la facultad de Montpellier, hiciese un viaje por la América meridional a expensas del gobierno, para buscar plantas y árboles que se podrían traer a Francia y a nuestras colonias 5 .

De lo que se trataba era de sustentar a los hombres: el botánico André Thouin precisaba a su amigo Dombey cuál podría ser, a su parecer, la misión que se le iba a confiar:

Este ministro Turgot le destina, Señor, a una comisión secreta; por lo que puedo juzgar, es para un viaje de muy largo curso, y para ir a buscar producciones que se quisieran naturalizar en nuestros climas. Lo que me deja creer esto, es que el señor Turgot me ha pedido una memoria detallada de las plantas y árboles extraños útiles a las artes y a la alimentación de los hombres que se podrían cultivar en Córcega o en Provenza ${ }^{6}$.

Las tentativas de aclimatación de las plantas exóticas no eran recientes, porque tenemos ejemplos precisos de ellas en el siglo XVII: a partir de 1636, se naturalizaron en el Jardín de las Plantas de París naranjos, limoneros, acacias de Egipto, palmeras, cañas de azúcar y, más tarde,

\footnotetext{
${ }^{4}$ Citado por Haмy, Ernest-Théodore (1905), Joséph Dombey, médecin, naturaliste, archéologue, explorateur du Pérou, du Chili et du Brésil (1778-1785). Sa vie, son œuvre, sa correspondance, avec un choix de pièces relatives à sa mission, París: E. Gilmoto, "Avantpropos", p. II.

${ }^{5}$ Clugny (1776), Carta a Vergennes, Versalles, 24 de agosto. En: Hamy (1905), p. 307.

6 Thouin, André (1775), Carta a J. Dombey de agosto. En: Hamy (1905), p. 3.
} 
árboles de té, cafetales, cacaos; y sabemos que Fagon, intendente de dicho establecimiento, curó el paludismo de Luis XIV con quina de su producción ${ }^{7}$.

Sin embargo, en el siglo XVIII se sistematizó la prospección, se impuso el depósito de las novedades y se previeron lugares de recepción, como el jardín de los boticarios de Nantes, colocado bajo la dependencia del de París, para las que vinieran del Atlántico ${ }^{8}$, o el de Hyères, propuesto por Condorcet para las que procedieran del Mediterráneo9.

Esta perspectiva llevó a proyectar la implantación en Francia de plantas no europeas, como la quinua ${ }^{10}$ o a tratar de aclimatar otras, como la batata (en La Rochelle) ${ }^{11}$ o el arroz (en Auvernia) ${ }^{12}$. Cabe decir que tales intentos fracasaron; en cambio, otra planta americana, conocida desde hace decenios, acabó por tener gran éxito en Europa en aquella época: la patata.

\section{La difusión de la patata en Europa}

Los españoles descubrieron este tubérculo durante la conquista del Perú; es, pues, bastante lógico que las primeras menciones se encuentren en los escritos de los primeros cronistas de la América del sur: Agustín de Zárate (Historia del descubrimiento y conquista de la provincia del Perú),

7 LaIssus, Yves (1964), «Le Jardin du roi». En: R. Taton (dir.): Enseignement et diffusion des sciences en France au XVIIIeme siècle. París, Hermann, p. 293, n. 2.

8 Ordonnance [...] pour assujetir lers capitaines des navires de Nantes $d$ 'apporter des graines et des plantes des colonies des pays étrangers pour le Jardin des plantes médicinales établi à Nantes. Fontainebleau, 9 sept. 1726. B. N. París, cote F 23623 (473). Ed.: NANTES, N. VERGER, s. f., 4. ${ }^{\circ}, 3$ páginas.

9 Condorcet (1774), Carta a Turgot, julio. En: Henry, Charles (1883), Correspondance inédite de Condorcet et de Turgot (1770-1779) publiée avec des notes et une introduction. París: Caravay Frères, p. 181.

${ }^{10}$ DombeY, Joséph (1778), Carta a A. Thouin, Lima, 11 de diciembre. En: HamY (1905), p. 42.

11 Cf. Labat, Padre Jean-Baptiste (1742), Nouveau voyage aux îles de l'Amérique [1696]. París: Théodore le Gras, II, pp. 400-401 et 406.

12 SoREAU, Edmond (1952), L'Agriculture du XVII eme siècle à la fin du XVIII ${ }^{\text {eme }}$ siècle. vol. 4 de la col. «L'Agriculture à travers les âges». París: E. de Boccard, p. 223; y DuPONT DE Nemours, P. S. (1782), Mémoires sur la vie et les ouvrages de M. Turgot, Ministre d'État. Filadelfia, II, pp. 188-189. 
Pedro Cieza de León (Crónica del Perú) y Francisco LóPEz de Gómara (Historia general de las Indias).

Según el irlandés, residente en España, William Bowles (Introducción a la historia natural y a la geografía física de España, 1775), las primeras patatas fueron cultivadas en Galicia. ¿Por qué? ¿Porque algunos navíos, de vuelta del Nuevo Mundo, abordaron allí, como se dice a veces? Quizás. ¿Porque el clima de dicha provincia le conviene mejor? Es más probable, si observamos que, para Francia, fue en Bretaña, de clima bastante parecido, donde se naturalizó primero.

De España, donde casi no tuvo difusión, pasó a Italia, en los petates de los soldados españoles que, después de participar en la conquista de América, iban a defender, contra los franceses, los territorios del Milanés o de Nápoles. En la segunda mitad del siglo XVI, parece bastante bien implantada en la península italiana, donde ya la conocían varios botánicos, como Girolamo Cárdano, de Pavía ${ }^{13}$.

Al comenzar el siglo siguiente, Charles de l'Écluse (Clusius en botánica) decía que «estos tubérculos se habían vuelto tan comunes en algunas comarcas de Italia que ya se solían comer con carne de carnero y que con ellos se engordaban los puercos ${ }^{14}$. Este botánico, que realizó la primera descripción científica de la planta, en su Rariorum plantarum historia (1601) y le dio el nombre latín de papa peruvianorum, señalaba que vulgarmente se llamaban las patatas «trufas de tierra», taratuffoli, en Ita$\mathrm{lia}^{15}$ (donde, por otra parte, la palabra tartuffi se sigue utilizando hoy día).

De la península italiana la patata pasó a Alemania, como lo confirma el nombre que tomó en aquel país, Kartoffel, que es una deformación del nombre italiano anteriormente adoptado.

Mientras tanto, a finales del siglo XVI, otros soldados españoles la habían llevado a las posesiones noreuropeas de Su Majestad Católica: Países Bajos, Franco Condado, Borgoña.

\footnotetext{
13 VIREY, Joséph Julien (1818), "Pomme de terre (Recherches sur son origine et l'époque de son introduction en Europe)", Nouveau dictionnaire d'histoire naturelle appliquée aux Arts, à l'Agriculture, à l'Économie rurale et domestique, à la Médecine, etc. par une Société de Naturalistes et d'Agriculteurs. París: Déterville (nueva ed.), XXVII, p. 528.

${ }^{14}$ Ibid., p. 529.

15 Ibid.; y Biographie universelle ancienne et moderne (1819), París: L. G. Michaud, XXIII, art. "L'Écluse», pp. 521b-522a.
} 
Notemos, de paso, que la introducción de este tubérculo en Europa por los ingleses, muy frecuentemente aludida como anterior a las demás vías de penetración, es muy discutible. Es verdad que las islas Británicas obtuvieron esta planta de su colonia de Virginia: las primeras han sido efectivamente traídas de allí por Francis Drake en 1590 (quien las había tomado, él mismo, en Nueva Granada, probablemente con ocasión de una de sus expediciones de los años 1570-1572); en 1597, el botánico Gerard recibía a su vez algunas de aquel territorio, de donde Walter Raleigh importó también otras (pero parece que en mayor cantidad), en $1623^{16}$. Se notará, sin embargo, que el cultivo de las patatas no se difundió hasta el siglo XVII, primero en Irlanda (que pasaba graves hambrunas, porque Londres confiscaba en su provecho toda la producción de cereales de la gran isla), luego en Inglaterra, donde Lancashire parece haber sido la primera región en recibirla ${ }^{17}$.

Finalmente, toda la Europa occidental del siglo XVII se aprovechaba de sus virtudes, como Suiza «donde se ha multiplicado tanto que ha pasado a ser el alimento de las dos terceras partes del pueblo ${ }^{18}$. Ya en la primera mitad del siglo XVIII, se instauraba la tradición de la patata frita belga:

Los flamencos no toman comida en que no entren patatas, hasta en casa de las personas más acomodadas; es una delicia para ellos ${ }^{19}$.

Curiosamente, Francia y España estaban ausentes. Fue preciso esperar la segunda parte del siglo ilustrado para que los dos países se lanzasen verdaderamente a la práctica de este cultivo $\mathrm{y}$, sobre todo, para que éste se volviese un componente importante de la alimentación de los ciudadanos de ambos países.

6 VIREY, J. J. (1818), p. 527.

17 Ibid., y Mustel (1767), "Mémoire sur les pommes de terre et sur le pain économique, lu à la Société d'Agriculture de Rouen", Journal de l'Agriculture, du Commerce et des Finances. París: Knapen, julio, p. 105.

18 Ibid.

${ }^{19}$ Carta de un terrateniente de la Somme al intendente de Amiens (1768), Archivos Departamentales de la Somme, C 137, pieza 12. En: M. Chaulanges et alii (1961), Textes historiques: Le XVIII ${ }^{e ̀ m e}$ siècle, 1715-1789. París: Delagrave, p. 91. 


\section{JEAN-PIERRE CLÉMENT}

\section{La campaña en favor de la patata}

Para ello, fue necesario emprender una verdadera campaña «publicitaria» en favor de nuestro tubérculo; fue dirigida por algunos especialistas (médicos, farmacéuticos, higienistas, botánicos, etc.). Primero, fue menester fijar las cosas: en 1762, el botánico Duhamel de Monceau daba por fin a esta planta, que se llamaba a veces truffe (trufa), a veces morelle (morela), su nombre definitivo en francés de pomme de terre. En 1769, la academia de Besançon ofreció un premio a la memoria que propusiese el producto vegetal más capaz para sustituir provisionalmente al pan. Antoine Parmentier, un tiempo farmacéutico auxiliar en el ejército de Hannover (1756), había conocido la patata en Alemania; hizo de ella el tema de su disertación y ganó el primer premio, en 1771, con su Examen químico de la patata (publicado en París en 1777). De Francia, donde su cultivo se extendió, los efectos repercutieron en España que, a su vez, acabó por quedar convencida del interés de su producción para los hombres. Ya se había entrado en el siglo XIX.

Esta campaña era tanto más necesaria cuanto que los obstáculos eran numerosos al cultivo de esta planta. En el siglo XVII, por ejemplo, el Parlamento de Besançon lo había prohibido, alegando que la patata era perniciosa y podía dar la lepra ${ }^{20}$. En el siguiente, no hubo tanta exageración; sin embargo, se consideraba que era un mal alimento, apenas bueno para los cerdos y que aun era «la peor de todas las legumbres», como lo afirmaba un libro de cocina de 1748 titulado la Escuela de las sopas. Y Le Grand d'Aussy explicaba, algunos decenios después, lo que había que entender con esto:

El gusto pastoso, la insipidez natural, la cualidad malsana de este alimento, que es flatuloso e indigesto, to han hecho desechar de las casas delicadas y ofrecer al pueblo, cuyo paladar más grosero y estómago más vigoroso se contentan con cuanto es capaz de apagar su hambre ${ }^{21}$.

\footnotetext{
20 FeYtaud, J. (1949), La pomme de terre. Paris: P. U. F. (Coll. «Que-sais-je?, n. ${ }^{\circ} 372$ ), p. 25 .

${ }^{21}$ Histoire de la vie privée (1783), cit. par Feytaud (1949), p. 25.
} 
Es obvio que la patata estaba muy lejos, en aquella época, de tener la cualidades gustativas de las especies actualmente comercializadas, como las Apollo, las Spunta o también las más antiguas, con nombres muy conocidos de las amas de casa, como la Bintje, la BF 15 o la Roseval. Sin embargo, a fines de la época de las Luces, grandes progresos habían sido realizados en esta materia, gracias a un mejor conocimiento del cultivo (el aporcamiento, por ejemplo) de este tubérculo, que acabó así por ser cada vez menos amargo, más grueso y con tegumento progresivamente menos espeso.

En realidad, el gran obstáculo a su consumo por el pueblo parece haber sido de orden sicológico: la patata se consideraba entonces como un alimento para ganados y no para hombres.

Esto animó a algunos personajes a tratar de hacerle perder esta imagen de cebo para animales para darle la de un alimento para humanos; por ejemplo, imponiéndola a sus servidores, como la señora de Fortmanoir, en el departamento de la Somme, de la que habla un documento de $1768^{22}$.

Pero esto quedaba todavía insuficiente, porque, aun así, seguía apreciándose la patata como un alimento socialmente inferior, como la comida de los pobres y de los míseros, o de los criados en el mejor de los casos. Otros, por consiguiente, iban a ir más lejos e intentar difundir su uso entre las clases más acomodadas de la sociedad. Fue el caso de Turgot quien, después de introducir su cultivo en su intendencia de Lemosin, y considerándola como una posible solución a la penuria que padecía esta pobre provincia, quedó pronto decepcionado por la postura de rechazo popular que le fue opuesta, porque la gente sencilla no veía en esta legumbre sino «un alimento por debajo de la dignidad de la especie humana ${ }^{23}$. La solución consistió entonces, para él, en mandarla servir en su mesa cuando recibía a personas principales de la región, dando así «el gusto de ellas a las primeras clases de ciudadanos», según la fórmula de Condorcet ${ }^{24}$.

\footnotetext{
22 Carta de un terrateniente de la Somme (1768), p. 91. p. 31 .

23 Condorcet (1787), Vie de Monsieur Turgot. Berna: Kirchberger et Hatter,

${ }^{24}$ Ibid.
} 


\section{JEAN-PIERRE CLÉMENT}

Los partidarios de la patata trataron, pues, de hacer que se considerase como un alimento "noble». Esta perspectiva es la que permite entender la actitud de Luis XIV paseándose todo el día 25 de agosto de 1768, con una flor de patata en la solapa de su traje de corte ${ }^{25}$.

Al mismo tiempo, los propagandistas de este tubérculo demostraron que su cultivo era, a la vez, fácil, rentable y, obviamente, útil:

El cultivo de esta planta es sencillo y muy fácil, cualquier tipo de tierra le conviene, hasta la arena [... I Su producción, con tal que sea algo cuidada, es incalculable ${ }^{26}$.

Y el mismo autor añadía que Geoffroy Saint-Hilaire decía haber obtenido 986 patatas con un solo tubérculo, y que él mismo había recogido algunas que pesaban ihasta 6 y 7 libras! ${ }^{27}$ Cifras muy sorprendentes, cuando se conoce un poco el rendimiento de esta planta, pero pienso que no hay que tomar estas afirmaciones como artículo de fe: sólo son declaraciones provocativas.

La gran ventaja que presenta este tubérculo es que, contrariamente a los cereales que suelen constituir el pilar principal de la alimentación bajo el Antiguo Régimen, está protegido del hielo y otras intemperies, ya que es una «míes subterránea preservada por la naturaleza contra las tempestades y las calamidades del cielo» ${ }^{28}$.

La consecuencia mayor es que la misma superficie sembrada con patatas da de comer a dos veces más personas que si fuera cultivada con

\footnotetext{
25 Por un guiño de la Historia y la gracia de los organizadores de este simposio, la presente ponencia fue leída el 25 de agosto de 1993, ¡exactamente 225 años después de este día famoso!

${ }^{26}$ GoubE (1794), Instruction abrégée sur l'usage de la pomme de terre, sa panification, ses propriétés et sa culture, proposée aux citoyens de la campagne par le citoyen... président du district de Gournay, département de la Séine-Inlérieure. Gournay: Impr. de Leleux et Dieudonné, impresores del Distrito, p. 4.

27 Ibid.

28 VIREY (1818), p. 526. En otro artículo del mismo diccionario, Parmentier escribe que su «mies no está tan expuesta [como el trigo] a la inclemencia de las estaciones» (PARmentier, Antoine (1818), "Pomme de terre [Économie rurale et domestique de la]", Nouveau dictionnaire d'histoire naturelle appliquée aux Arts, à l'Agriculture, à l'Économie rurale et domestique, à la Médecine, etc. par une Société de Naturalistes et d'Agriculteurs. París: Déterville, nueva ed., XXVII, p. 548).
} 
trigo ${ }^{29}$. Tal era el fin principal de esta campaña propagandística: era imprescindible, para las autoridades, compensar las rupturas alimenticias y evitar las hambres que asolaban regularmente el país.

Los partidarios de este cultivo recordaban, además, que presentaba otras ventajas. Y ante todo un interés industrial; en efecto, "su almidón lava y quita la grasa mejor que el jabón» ${ }^{30}$ y, por si esto fuera poco, «conserva los colores de los tejidos» ${ }^{31}$.

La planta pasaba, a sus ojos, por favorecer también la cría del ganado, porque era un excelente cebo para la mayor parte de los animales; se dice en efecto en este texto que ella «alimenta perfectamente los caballos, los bueyes, los pavos, los pollos, los carneros, los cerdos, y los engorda en muy poco tiempo ${ }^{32}$. Además de la rentabilidad mejorada por la mayor brevedad del tiempo de cría, los efectos sobre los animales debían de ser muy positivos, puesto que, gracias a este rico alimento, "su grasa es blanca y delicada; [la patata] proporciona mucha y excelente leche a las vacas y a las cabras» ${ }^{33}$.

Como se puede observar aquí, se vuelve siempre a los hombres: el mismo autor ya explicaba, en la página anterior, que la patata da una leche de muy buena calidad a las nodrizas. Y, claro,

los niños a quienes se la da [la patata] como alimento se tornan fuertes y vigorosos, lo que prueba cuán amiga es del hombre ${ }^{34}$.

\section{El argumento gastronómico}

Pero no podemos contentarnos con esta descripción; en efecto, la propaganda en favor de la patata tomó rápidamente una orientación social. Uno de los protagonistas, llamado Mustel, insistió, por ejemplo, sobre el hecho de que allende el Rin, donde se había difundido desde hacía mucho

\footnotetext{
29 Parmentier (1818), p. 548.

30 Parmentier fue el primero que supo extraer el almidón de la patata (cf. MAGNIEN y DEU (1809), Dictionnaire des productions de la nature et de l'art qui ont fait l'objet du commerce de la France. París Antoine Sailleul, I, p. 407).

${ }^{31}$ GoubÉ (1794), p. 2.

32 Ibid., p. 3.

33 Ibid., p. 3.

34 Ibid., p. 2.
} 


\section{JEAN-PIERRE CLÉMENT}

tiempo, la patata era consumida por las clases acomodadas de la sociedad, que la comían por gusto (y ya no sólo por necesidad). La argumentación venía hábilmente presentada, porque escribía este autor:

He visto servir de ellas en Alemania, sazonadas de diversas maneras, en la mesa de los Príncipes, en la que se habría menospreciado servir habas y otras legumbres semejantes ${ }^{35}$.

Es decir, que la alta sociedad germánica parece colocar la patata por encima de las legumbres ordinariamente comidas por los franceses. $\mathrm{He}$ aquí un argumento de peso en un país en el que está despuntando el nacionalismo.

Pero no era suficiente, y se añadieron, en la mayor parte de los textos que trataron de la cuestión, incentivos gastronómicos:

Un poco de mantequilla, de grasa, de tocino o de aceite, nata, leche, miel bastan para hacer de ella un excelente comestible ${ }^{36}$.

Los higienistas fueron a veces más precisos en sus indicaciones, al aconsejar múltiples preparaciones posibles, sencillas en su realización y agradables de comer: estofadas, con salsa de harina o blanca, fritas, como relleno en las aves, etc. ${ }^{37}$, o también preconizaron que se las hicieran cocer en agua o en la ceniza caliente ${ }^{38}$. ¡Cuántas precisiones muy propias para excitar el gusto y agudizar el apetito!

Para que se pudiera consumir en todo tiempo, Parmentier propuso un procedimiento de conservación de esta legumbre; es interesante, porque lo completa con una presentación de las diversas posibilidades de utilización: primero, dice, hay que sancochar las patatas haciéndolas hervir en agua salada, luego se las corta en rebanadas que se ponen a secar sobre un horno de panadero; se endurecen y se pueden conservar así un tiempo indefinido. Cuando se las quiere utilizar, basta con echarlas al agua a

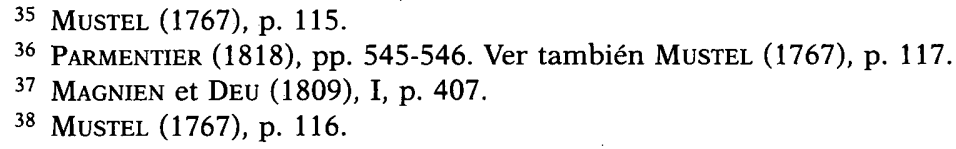


fuego lento; estas rebanadas se pueden también reducir a polvo, para hacer con él puré o sopas "muy saludables» ${ }^{39}$.

Empero, no se puede olvidar que, en aquel entonces, en Francia quizás más que en otras partes, el alimento básico, era el pan. Era, por consiguiente lógico que los especialistas llegasen a proponer el empleo de la patata en la fabricación de esta comida esencial. El higienista Mustel explicaba así que el cura del pueblo de Arton, en Bretaña, había elaborado pan, mezclando dos terceras partes de pulpa de patata con una tercera parte de harina de centeno. Él mismo ofrecía una receta que mezclaba harina de trigo y patata reducida a polvo ${ }^{40}$. Este pan, dice Mustel, es de buena calidad: es blanco y ligero, como pan candeal, tiene buen sabor y se conserva bien ${ }^{41}$.

Parmentier, por su parte, propuso también un pan a base de patatas, según un principio parecido. Más tarde, logró poner a punto una fórmula que ahorraba totalmente el gasto de harina de trigo y se reveló, por consiguiente, mucho más interesante en aquellos momentos en que las malas cosechas de cereales eran bastante frecuentes ${ }^{42}$ :

el pan se compone de mitad almidón mitad pulpa [de patata]; añadió una quinta parte de agua para amasarlo y obtuvo una libra de pan con tres libras de patatas ${ }^{43}$.

Pese a las cualidades anunciadas de este "pan", hemos de observar que el éxito de la receta resultó bastante tibio y que no sobrevivió a su autor. Queda, sin embargo, ante el tribunal de la Historia la voluntad del sabio para sacar a sus hermanos humanos de la miseria.

Más sorprendente todavía, en esta misma campaña, fue la receta para elaborar queso con patatas. No se debe a Parmentier, sino a un curioso, alemán de nación; había anunciado éste, en algunos periódicos de la época, que comunicaría el secreto de la fórmula «contra una razonable recompensa». Samuel Engel explica, en la Enciclopedia que ha mandado

\footnotetext{
39 Parmentier (1818), p. 542.

40 Mustel (1767), p. 117.

41 Mustel (1767), p. 124.

42 Ver su memoria de 1779 sobre la Manière de faire le pain de pomme de terre, sans mélanger de farine.

43 Magnien et Deu (1809), I, p. 407.
} 


\section{JEAN-PIERRE CLÉMENT}

la cantidad deseada al inventor y que, a su vez (pero gratis), ofrece la receta a los lectores del (famoso) diccionario ${ }^{44}$. Esta consiste en mezclar patatas hervidas, cuidadosamente trituradas, con leche preparada para el queso, en una proporción de 2/3-1/3. Los quesos así elaborados son, según dice, muy ricos, y, añade, «cuantos más viejos son, más calidad y delicadeza adquieren ${ }^{45}$.

Se observará que, como en el caso del pan, se insiste en el placer gustativo de la preparación realizada. El combate que llevaron Parmentier y algunos más fue un combate en favor de la calidad: no se trataba sólo de hacer comer patatas a todos, sino también de incitar a la gente de las clases consideradas como superiores a consumirlas. Por lo tanto, resultaba primordial el argumento de la calidad gustativa del producto.

\section{Las ollas americanas}

La cocción al vapor se justifica con los mismos argumentos ${ }^{46}$. Parmentier observa que, al hacer hervir las patatas en agua - según la usanza habitual一, pierden todo su sabor, que «todas se vuelven sosas». Añade: «Es, pues, necesario cambiar de método» 47 , y propone un procedimiento nuevo que llama ollas americanas. Es una práctica muy superior, a nivel alimenticio, al cocimiento en el agua, la única conocida de los Europeos hasta entonces, explica el mexicano Alzate:

Esta práctica es utilísima y de mucho aprecio por lo que mira a la salud y uso de alimentos; porque los vegetales sumergidos en agua, que-

44 ENGEL, Samuel (1778), "Truffe», Encyclopédie. Genève, Pellet, 34, p. 376a.

45 Ibid., p. 376b.

46 Ignoro cuando Parmentier ha descrito por primera vez este procedimiento: existe primero un análisis técnico en un informe presentado por La Rochefoucauld-Liancourt, Cadet de Vaux y Saintlean de Crèvecoeur, titulado «Rapport sur la marmite américaine de Parmentier" y publicado en las Mémoires de la Société Royale d'Agriculture (París, trimestre de primavera de 1786, p. 107 sq.). El mismo Parmentier ha publicado una descripción de este sistema de cocción en su Bihliothèque physico-économique (París, 1788, t. I, pp. 216 sq.) y en el artículo «Pomme de terre» que escribió para el Nouveau dictionnare d'histoire naturelle appliquée aux Arts, à l'Agriculture, à l'Économie rurale et domestique, à la Médecine, etc. por una Sociedad de Naturalistas y Agricultores (París: Déterville, 1818, nueva ed., t. XXVII, pp. 544 sq.).

47 Parmentier (1818), p. 544. 


\section{PARMENTIER, LAS PATATAS Y LAS OLLAS AMERICANAS}

dan privados de sus partículas nutritivas y útiles; y como esta agua por lo regular se arroja por inútil, el hombre tan solamente devora el esqueleto de la planta ${ }^{48}$.

En cuanto a Parmentier, describe así el sistema:

Cualquier olla de hierro colado, cualquier caldera de cobre es útil para esta operación: poco importa la vasija de la que se sirva, con tal que se encuentren en ella tres o cuatro pulgadas de agua, que las patatas puestas ahí estén también alejadas de ésta de algunas pulgadas, y que venga provista de una tapa que cierre con bastante precisión para oponerse al escape del vapor del agua hirviente.

Una alambrera o un sencillo encañizado de mimbre que cabría en una olla, a alguna distancia del fondo y de las paredes, bastaría, con la precaución de cerrar con precisión la olla. Acabando el agua por reducirse con el hervor, viene empujada hacia las raíces ${ }^{49}$, las baña, las calienta de modo a determinar el cocimiento en su propia humedad. [...] El ligero desperdicio que experimentan al cocer así, se vuelve en provecho de su sabor ${ }^{50}$.

Una vez más, se ponía en evidencia el argumento del gusto, confirmando así que la sociedad francesa (y probablemente la de toda la Europa occidental) vivía, en aquella época, un progreso cualitativo: ya no se trataba solamente de alimentar, sino de alimentar mejor, es decir de tomar placer en comer. Se iba acercando, en Francia, la tormenta revolucionaria; una de sus consecuencias fue que los grandes cocineros de las familias aristócratas, que veían a sus amos morir en la guillotina o expatriarse, se encontraron de repente desempleados y abrieron los primeros grandes restaurantes parisinos o se pusieron al servicio de las ricas casas burguesas, difundiendo así en un círculo más amplio la comida refina$\mathrm{da}^{51}$.

48 Alzate y Ramírez, José Antonio (1792), «Del chayote», Gaceta de Literatura de México, 31 de enero.

${ }^{49}$ Se equivoca Parmentier cuando considera que las patatas son raíces; se trata, en realidad, de tubérculos que crecen sobre estolones, tallos subterráneos procedentes de la patata madre.

50 Parmentier (1818), p. 544.

51 Cf. el excellente libro de Jean-Paul Aron (1973), Le Mangeur du XIXe siècle. París: R. Laffont, Biblioteca «Médiations», n. ${ }^{\circ}$ 142, pp. 20-47. 


\section{JEAN-PIERRE CLÉMENT}

España conoció, a su vez, la misma campaña, sólo que algo atenuada. El Semanario de Agricultura publicó, en los primeros años del siglo XIX, varios textos que iban todos por el mismo camino. Muchos eran transcripción de artículos franceses, íntegramente traducidos al castellano, como el en que Cadet de Vaux describía también las ollas americanas de Parmentier ${ }^{52}$.

Venían expuestos ahí varios argumentos destinados a incitar a la gente a emplear este "nuevo» modo de cocción, insistiendo en la mejor calidad gustativa de las legumbres así preparadas, porque conservan su sabor y toda su agua natural ${ }^{53}$. Para mostrar el interés de este tratamiento, se indicaba que otras legumbres podían, también aprovecharse de él:

Los espárragos cocidos al vapor no se parecen en nada a los que se cuecen en agua, porque salen [...] con todo su sabor y con el color muy subido $^{54}$

Se notará que al interés nutritivo se añade el placer del paladar y el de los ojos, ya que este procedimiento aviva los colores de las legumbres, poniéndolas más atractivas. Es evidente que hay aquí un salto cualitativo en la alimentación: la gente de la época comienza a interesarse por la presentación de los platos y no sólo por la cantidad o el volumen de alimento. Hasta entonces, cuando se trataba de comer, se hablaba sobre todo de "capones gordos», de "hermosos faisanes», de "pellas de mantequilla», de "montones de frutas muy variadas", de la abundancia de una alimentación rica en grasa y en número de platos; de ahí en adelante, parece que se recomienden los alimentos bien preparados y presentados de modo a abrir el apetito. El propósito de los higienistas, pues, es doble: por una parte, alimentar a una gran masa de gente que suele pasar hambre en crisis alimenticias regulares, y, por otra parte, incitar a los que tienen generalmente de que comer, a nutrirse mejor, es decir a tener una alimentación de calidad superior a la que tenían hasta ahí.

\footnotetext{
52 CADET DE VAUX, Antoine (1802), "De la preparación de algunos alimentos y economía de combustible», Semanario de Agricultura y Artes dirigido a los Párrocos. Madrid, XIII, pp. 143-144.

53 Cadet de Vaux (1802), p. 144.

${ }^{54}$ Ibid.
} 
Este modo de preparación de las ollas americanas presenta también la ventaja de permitir un ahorro de combustible. El mismo autor explica que, gracias a él, se pueden cocer muchas legumbres a un tiempo. El conde Rumford, célebre filántropo americano-inglés de la época, precisa que el sistema antiguo de cocimiento en agua hacía perder las 7/8 partes del calor suministrado, cuando las ollas americanas permiten ahorrar las $9 / 10$ partes de la energía dada ${ }^{55}$.

Y el químico Cadet de Vaux repite los dos últimos argumentos: de un lado, este procedimiento "nuevo» da alimentos gustosos (lo que seduce a la gente acomodada) y, por otro lado, el ahorro de energía realizado es muy benéfico para las familias pobres:

Esto de conservar mejor sabor es un punto importante para los ricos, que no reparan en gastar leña y carbón ¡cuántas pobres madres calentaran los helados miembros de sus hijos con lo que se quema superfluamente en las cocinas de los ricos! Así todos nos propusiésemos economizar en esta parte cuanto sea posible, para evitar la total devastación de nuestros montes, y conservar a nuestros nietos un artículo tan indispensable de que les priva nuestra prodigalidad ${ }^{56}$.

Como se puede observar, todo acaba por un discurso ecológico eminentemente moderno.

Pero la historia no acaba aquí. Porque la invención de Parmentier no es verdaderamente su invención. En efecto, el periodista y vulgarizador científico mexicano, José Antonio Alzate y Ramírez, recuerda, en su Gaceta de Literatura de México, que el procedimiento de las ollas americanas es, en realidad, una práctica habitual de los indios de su país.

El célebre Parmentier, químico útil, por cuanto no se ocupa en operaciones curiosas, sino en las que se dirigen al sustento de los hombres, parece que ha introducido la práctica de los mexicanos de cocer los alimentos al vapor del agua, y las máquinas que ideó con este motivo (segu-

55 RuMFord, Conde (1800), «Ensayo sexto político-económico [...] sobre la economía del combustible», Semanario de Agricultura y Artes dirigido a los Párrocos. Madrid, VII, pp. 324-325.

56 CADET de VAuX (1802), p. 144. 


\section{JEAN-PIERRE CLÉMENT}

ramente no serán tan sencillas como las de los indios) las publicó con el título de marmitas u ollas americanas ${ }^{57}$.

Y hace del procedimiento la siguiente descripción, que es interesante comparar con la del francés:

En una olla, como a cuatro dedos de distancia del fondo, [los indios mexicanos] colocan dos maderos delgados, que forman una cruz: sobre éstos extienden una poca de paja o yerbas secas, y sobre este apoyo o cama que los indios llaman tlapestle, van colocando chayotes, camotes u otras muchísimas frutas; llenan con agua el espacio comprendido entre el fondo de la olla o vasija y los maderos; la colocan sobre el fuego, tapan la boca con una cazuela, y el hervor del agua cuece los frutos en virtud del vapor que circula en el interior de la vasija ${ }^{58}$.

Se nota que las dos descripciones están bastante cercanas una a otra, y se puede concluir que Alzate se equivoca cuando escribe:

El indio con vasijas de poco valor efectúa lo que Parmentier propone se ejecute con maquinarias costosas ${ }^{59}$.

Parmentier, en efecto, no propone aquí ningún material complicado, ningún objeto caro, sino los utensilios corrientes en una cocina.

Gracias a muchos esfuerzos supo compartir con todos su entusiasmo hacia esta legumbre que tenía por excelente y consideraba como un verdadero don del cielo:

Por fin, es cierto que es, entre todas las producciones de las dos Indias, aquélla cuya adquisición debe bendecir más Europa, porque no ha costado ni crímenes ni lágrimas a la humanidad ${ }^{60}$.

57 AlzATE y RAMÍREZ (1792).

58. Ibid.

59 Ibid.

60 Parmentier (1818), p. 532. 
Es una visión obviamente muy idealizada de las cosas, porque el francés se olvida, en su ímpetu, de que los Europeos conocieron la patata a consecuencia de la conquista del Perú que no fue, ni mucho menos, una empresa dulce y humana. En realidad, parece que el gran higienista considere esta planta como externa a la Conquista, probablemente porque su difusión en su país y en el vecino intervino mucho tiempo después de la empresa americana. Existe, en efecto, un distanciamiento, y si no se está muy atento a los acontecimientos, la patata puede, por lo tanto, pasar por un resultado benéfico de las expediciones científicas del siglo XVIII. Es cierto que dichas empresas han aportado a Europa miles y miles de plantas nuevas, y que uno de sus fines principales era mejorar la alimentación de los europeos. A pesar de la relativa antigüedad de su descubrimiento (unos dos siglos), la patata, prácticamente ignorada de los franceses y de los españoles hasta las Luces, se sintió como algo recién descubierto; cumplió además con el objetivo arriba enunciado - y que había sido asignado a las expediciones científicas-: dar de comer a los hambrientos. Es decir que la asimilación, más o menos inconsciente, con las expediciones científicas de siglo XVIII era algo lógico y comprensible.

En efecto, a lo largo de su campaña "promocional», Parmentier y los que comparten su opinión sobre el asunto observan que esta legumbre da muy bien de comer a los hombres en los países en que ha sido implantada (Irlanda, por ejemplo, o Alemania) y que, gracias a ella, ya no se producen las hambres. En el contexto de crisis social permanente de la épo$\mathrm{ca}$, es un aporte esencial. Se entiende su entusiasmo, aunque sea algo ciego. En la misma vena, escribe Joséph Julien Virey:

¿Quién, pues, ha apartado gran parte de estas plagas [las hambres]? la patata [...] Así, multiplicar las subsistencias es multiplicar la materia viva, los hombres, los ganados; es duplicar en fuerza cada Estado; al hacer su suelo más productivo es evidente que en pocos siglos, Europa acrecentada por estos medios, se volverá mucho más populosa que jamás lo ha sido, y que, sola entonces, estará pronto dispuesta, sea a resistir al resto del universo, sea a conquistarlo. Será, pues, forzosamente preciso que la industria y la civilización se acrecienten hasta un estado desconocido hasta ahora en los anales del mundo, y desborden sobre el globo entero únicamente por la propagación de este tubérculo substancioso ${ }^{61}$.

61 VIREY (1818), p. 526. 


\section{JEAN-PIERRE CLÉMENT}

Se observa aquí una característica muy conocida de cuantos se interesan por las expediciones botánicas: el nacionalismo de la ciencia. Las intenciones de los higienistas y de las autoridades no fueron tan filantrópicas como parece. Y el general De Gaulle erraba, cuando escribía, en 1932, en su libro El filo de la espada, que la grandeza y potencia de una nación procede de la fuerza popular de su ejército y de sus jefes, y que

Napoleón, en el concurso de los grandes hombres, está siempre delante de Parmentier. 